\title{
LOS AÑOS DE FORMACIÓN (1977-1986)
}

\author{
Juan Luis López Cruces \\ Universidad de Almería \\ juanluis@ual.es
}

Coincidí con Isabel a los catorce años en el instituto Nicolás Salmerón de Almería. Ambos vivíamos en la zona centro de la ciudad y para ir y volver del instituto, que estaba entre la Ciudad Jardín y el Zapillo, debíamos cruzar la estación del tren cuatro veces al día. Como por aquel entonces no existía un paso elevado para atravesar la estación, cada vez que una de las vías estaba ocupada por una larga composición de vagones, fueran de mercancías o de pasajeros, no teníamos más remedio que subir a uno de ellos y bajar rápidamente por el lado opuesto, siempre con el temor de que se pusiera en movimiento de improviso. Fue durante esos trayectos entre casa y el instituto, más que en clase, cuando tuve ocasión de confraternizar con ella.

En el Nicolás Salmerón Isabel disfrutó del magisterio de tres magníficos profesores de Latín: Francisca Torres Martínez, Rafael Montes Torres y José Félix Campo Cacho. Las primeras nociones de Griego las aprendió con la igualmente memorable Clotilde Ruiz de la Torre Mayayo, y fue con ella con la que, durante el COU, vivimos una experiencia que en aquel tiempo interpretamos como un verdadero lujo. Hasta entonces habíamos estudiado en aulas masificadas, con más de cuarenta estudiantes distribuidos en tres hileras de bancas dobles, perfectamente alineadas e inamovibles. En cambio, las clases de Griego, que solo escogimos siete personas, las dimos en el seminario de Lenguas Clásicas alrededor de una gran mesa; todos podíamos vernos las caras con comodidad, lo que creaba una maravillosa sensación de igualdad dentro del grupo.

Cada vez que doña Clotilde debía ausentarse unos minutos por razones administrativas, Isabel se lanzaba a las estanterías de libros e inspeccionaba con atención la pequeña biblioteca de Latín y Griego que albergaba el seminario. Era una apasionada lectora. Desde muy joven captó la importancia de las lecturas compartidas para crear comunidad, de modo que leía obras numerosas y muy variadas. Recuerdo, cuando ya cursábamos estudios de Filología a comienzos de los años 80, su afición, entre otros, a Hesse, Borges, Cortázar, Benedetti, Yourcenar (Las memorias de Adriano pero también Fuegos, que conocí gracias a ella) y Eco con El nombre de la rosa, el gran boom editorial de aquellos años, que sumaba a una compleja intriga novelesca una atención infrecuente a la lengua latina y a la Antigüedad.

Sus gustos musicales eran igual de ricos y variados. Por aquella época le apasionaban cantautores como Silvio Rodríguez, Pablo Milanés, Luis Eduardo Aute y Lluis Llach; voces fascinantes como la de Ana Belén, que lo mismo cantaba en una 
canción un poema de Rafael Alberti que incluía en otra palabras en griego, el griego de Isabel: Agapimoú; escuchaba álbumes tan dispares como el Canto general de Neruda musicalizado por Theodorakis y Journey Through the Secret Life of Plants de Stevie Wonder; cuando llegó la Nueva Ola en los ochenta, también la acogió, curiosa y divertida. Tenía una extensa colección de casetes con música grabada, cuyas cartulinas uniformaba cubriéndolas con papel satinado amarillo, un color que la fascinó durante años.

No solo hubo libros y música: también teatro. Durante el primer curso de carrera (1981-1982) se incorporó al grupo de teatro Eos, del Colegio Universitario de Almería. Aquello fue una ventana de aire fresco abierta al mundo. En una Almería muy pequeña, con una limitada oferta cultural y un solo canal de televisión, el grupo de teatro le ofrecía enormes posibilidades de realización personal; no era solo un grupo de personas con exigencias intelectuales, sino también un lugar de juego, de jugar a ser otro y a pensar como otro. El grupo hizo su presentación en 1982 en el certamen teatral que tenía lugar por aquel entonces durante la Feria de Almería, a finales de agosto; llevó a la escena una adaptación de una obra de Dario Fo, que al mes siguiente formó parte de los actos de inauguración del curso académico 1982-1983 en el Colegio Universitario de Almería. A esa adaptación siguió una segunda obra, con la que tuvimos la sensación — juvenil, pero quizá justa - de haber alcanzado una suerte de excelencia colectiva. Se trataba de una creación del director del grupo, Antonio Aguilera Vita, llamada La Comedia. Era una reelaboración del mito de Electra en la que esta quería acabar no con su madre por haber matado a su padre, sino con este por haber matado a aquella, y todo ello — cómo no- en clave burlesca. Isabel representaba, entre otros papeles, el de una trágica, muy trágica Casandra, que veía todo negro, presa de lúgubres visiones de muerte, y nos hacía reír sin parar. $Y$ es que ella, como tantas personas tímidas que luchan por vencer su timidez, era una buena actriz. Fue un tiempo de muchas risas.

Su realización en el ámbito del grupo de teatro fue un complemento para su crecimiento personal. Isabel sabía estar sola tan bien como en grupo; es más, a menudo reclamaba ese espacio de intimidad en el que restañaba sus heridas y volvía a hacerse fuerte; porque si algo la caracterizaba eran su fortaleza y su decisión. Gracias a ese espacio propio se movía con libertad en todo tipo de reuniones sociales.

Cuando llegamos a la Universidad de Granada a cursar los dos últimos cursos de la carrera, no tardó mucho en congeniar con el resto de los compañeros de la clase gracias a su permanente sonrisa y su buen ánimo. Y, tal como nos había pasado durante el COU, en Granada revivimos la sensación de provilegio cuando en $4 .^{\circ}$ de Filología Clásica cursamos la asignatura de Griego Posclásico que impartía el profesor Mosjos Morfakidis; de nuevo una gran mesa en el seminario de Griego y un grupo de estudiantes que nos mirábamos como iguales. $\mathrm{Al}$ acabar ese curso, en el verano de 1985, once estudiantes de aquella asignatura — casi todos los que acabábamos de cursarla - fuimos a Tesalónica a seguir un curso de Griego Moderno. Tuvo allí un detalle que me impresionó y que demuestra su grado de honestidad: aunque por el examen de nivel le correspondía estar en la clase más avanzada de los que veníamos de Granada, decidió cambiarse al nivel inmediatamente inferior porque pensaba que la habían valorado demasiado bien. 
Durante aquella estancia Isabel descubrió una Grecia que no esperaba y que le aportaba más incluso que la antigua. Con el tiempo su griego fue mejorando, iy hasta qué punto! Nunca dejó de aprender y de esforzarse. Sabía hasta dónde podía llegar y nunca se amilanaba. Coincidimos en un congreso en Atenas en 1995, cuando comenzaba a hacerse un sitio en el mundo del neohelenismo, y recuerdo aún su aplomo. En una de las sesiones se nos sentó delante el escritor Pavlos Mátesis y, al verlo salir, ni corta ni perezosa, se levantó para intentar charlar con él. Y lo mismo le pasó con profesores para nosotros afamados: recuerdo cómo se preparaba para abordarlos y cómo trababa conversación con ellos con facilidad. Con su buen hacer a lo largo de los años, Isabel convirtió la Universidad de La Laguna en un lugar de visita obligada de los neohelenistas, atraídos por una excelente anfitriona que organizaba reuniones científicas con regularidad y promovía la traducción de obras de la literatura neogriega.

Mis últimos recuerdos de ella son de 2009. Organizó en la Excma. Diputación de Almería un acto de presentación de su nueva editorial, Intramar Ediciones, y en concreto de dos obras de Antonio Aguilera, una de ellas la versión revisada de aquella comedia que habíamos representado veinte años atrás y que entonces pasó a llamarse No me fastidies, Electra. El acto tuvo lugar en las Navidades de 2009 y en él Isabel logró reunirnos a los antiguos amigos del grupo de teatro. Al poco nos envió las fotos que había sacado de la celebración. Después, el silencio.

Concluyo. Isabel fue una gran luchadora, que supo mantener su individualidad y compaginarla con una incansable actividad investigadora y una intensa pasión por Grecia. Quiso a sus amigos, nos hizo reír con su humor y nos contagió su entusiasmo por la vida. 
